\title{
Involvement of glutathione in heat shock- and hydrogen peroxide-induced cadmium tolerance of rice (Oryza sativa L.) seedlings
}

\author{
Y.-Y. Chao • Y. T. Hsu • C. H. Kao
}

Received: 9 June 2008 / Accepted: 20 October 2008 / Published online: 8 November 2008

(C) Springer Science + Business Media B.V. 2008

\begin{abstract}
The role of reduced glutathione (GSH) in heat shock (HS)- and $\mathrm{H}_{2} \mathrm{O}_{2}$-induced protection of rice (Oryza sativa L., cv. Taichung 1) seedlings from $\mathrm{Cd}$ stress was investigated. HS- and $\mathrm{H}_{2} \mathrm{O}_{2}$-pretreatment resulted in an increase in GSH content in leaves of rice seedlings. Addition of exogenous GSH under non-HS conditions, which resulted in an increase in GSH in leaves, enhanced subsequent $\mathrm{Cd}$ tolerance of rice seedlings. Pretreatment with buthionine sulfoximine (BSO), a specific inhibitor of GSH synthesis, which effectively inhibited GSH content induced by HS and $\mathrm{H}_{2} \mathrm{O}_{2}$, reduced subsequent Cd tolerance. Furthermore, the effect of BSO on HS- and $\mathrm{H}_{2} \mathrm{O}_{2}$-induced GSH accumulation and toxicity by subsequent $\mathrm{Cd}$ stress can be reversed by the addition of GSH. The time-course analyses of HS in rice seedlings demonstrated that the accumulation of $\mathrm{H}_{2} \mathrm{O}_{2}$ preceded the increase in $\mathrm{GSH}$. Based on the data obtained in this study, it could be concluded that the early accumulation of $\mathrm{H}_{2} \mathrm{O}_{2}$ during HS signals the increase in GSH content, which in turn protects rice seedlings from oxidative damage caused by $\mathrm{Cd}$.
\end{abstract}

Keywords Cadmium - Glutathione · Heat shock · Hydrogen peroxide - Oryza sativa L. O Oxidative stress

Responsible Editor: Juan Barcelo.

Y.-Y. Chao • Y. T. Hsu • C. H. Kao $(\bowtie)$

Department of Agronomy, National Taiwan University,

Taipei, Taiwan, Republic of China

e-mail: kaoch@ntu.edu.tw
Abbreviations
APX Ascorbate peroxidase
BSO Buthionine sulfoximine
$\gamma$-EC $\gamma$-Glutamylcysteine
$\gamma$-ECS $\gamma$-EC synthetase
FW Initial fresh weight
GR Glutathione reductase
GSH Reduced glutathione
GSSG Glutathione disulfide
HS Heat shock
ROS Reactive oxygen species

\section{Introduction}

Heavy metal pollution has become a serious environmental and health problem. Cadmium $(\mathrm{Cd})$ is a toxic element found in various amounts in the soil. Plants take up Cd from the soil (Greger and Landberg 2008; Jarvis et al. 1976). Cd damages roots, reduces nutrient and water uptake, impairs photosynthesis, induces chlorosis, inhibits growth and finally results in cell death (Das et al. 1998). Although it does not directly produce hydroxyl radicals through Fenton or Haber-Weiss reactions, $\mathrm{Cd}$ can produce reactive oxygen species (ROS) including $\mathrm{H}_{2} \mathrm{O}_{2}$ and generates an oxidative stress (Cho and Seo 2005; Garnier et al. 2006; Hsu and Kao 2007a; Schützendübel and Polle 2002).

Glutathione ( $\gamma$-glutamylcystenylglycine, GSH) is widely distributed in eukaryotes and is an essential 
component of the cellular antioxidative defence system, which keeps ROS under control (Foyer and Nocotor 2005; Noctor and Foyer 1998; Rouhier et al. 2008). GSH is synthesized from two consecutive ATP-dependent reactions (Mendoza-Cózatl et al. 2005). In the first step $\gamma$-glutamylcysteine $(\gamma$-EC) is formed from L-glutamate and L-cysteine by $\gamma$-EC synthetase $(\gamma$-ECS). The second step is catalyzed by glutathione synthetase which adds glycine to the Cterminal of $\gamma$-EC forming GSH. When GSH is oxidized as part of its antioxidant activity, it forms glutathione disulfide (GSSG), the oxidized form of GSH. The glutathione reductase (GR) reduces GSSG back to GSH at the expense of NADPH. The ability to synthesize GSH appears to be crucial for protection from $\mathrm{Cd}$, as shown by the increased tolerance of plants with elevated levels of GSH as well as a decreased tolerance in plants with diminished levels of GSH (Howden et al. 1995; Pilon-Smits et al. 2000; Xiang et al. 2001; Zhu et al. 1999).

Prior exposure to heat shock (HS) temperatures has been shown to exhibit an acquired protection against Cd stress (Chen and Kao 1995a; Hsu and Kao 2007b; Neumann et al. 1994; Orzech and Burke 1988). Nieto-Sotelo and Ho (1986) demonstrated that maize roots under HS conditions have higher GSH level than those under non-HS. However, no data are available showing that HS-induced $\mathrm{Cd}$ tolerance is due to an enhancement of GSH biosynthesis in plants.

Because $\mathrm{H}_{2} \mathrm{O}_{2}$ is relatively stable and diffusible through membranes (in contrast with superoxide), it is now considered as a signal molecule for selective induction of defense mechanisms in plant cells (Chen et al. 1993; Prasad et al. 1994a, b) $\mathrm{H}_{2} \mathrm{O}_{2}$ treatment has been shown to enhance tolerance to chilling, heat, salt, and drought stresses (Azevedo Neto et al. 2005; Dat et al. 1998; Gechev et al. 2002; Gong et al. 2001; Lopez-Delgado et al. 1998; Prasad et al. 1994a, b; Uchida et al. 2002; Wahid et al. 2007; Yu et al. 2002; 2003). The $\mathrm{H}_{2} \mathrm{O}_{2}$-induced chilling tolerance in mung bean was established to be associated with an elevation of GSH (Yu et al. 2002; 20003).

Our recent data (Hsu and Kao 2007b) demonstrated that enhanced tolerance of rice seedlings to $\mathrm{Cd}$ stress was obtained by prior treatment of $\mathrm{HS}\left(3 \mathrm{~h}\right.$ at $45^{\circ} \mathrm{C}$ in darkness) or $\mathrm{H}_{2} \mathrm{O}_{2}$. In this study, we investigated the possible involvement of GSH in HS- and $\mathrm{H}_{2} \mathrm{O}_{2}$ induced $\mathrm{Cd}$ tolerance of rice seedlings.

\section{Materials and methods}

Plant material and treatments

Rice (Oryza sativa L., cv. Taichung Native 1) seeds were sterilized with $2.5 \%$ sodium hypochlorite for $15 \mathrm{~min}$ and washed extensively with distilled water. These seeds were then germinated in Petri dishes with wetted filter papers at $37^{\circ} \mathrm{C}$ in the dark. After $48 \mathrm{~h}$ incubation, uniformly germinated seeds were selected and cultivated in a $250 \mathrm{ml}$ beaker containing halfstrength Kimura B solution containing the following macro- and micro-elements: $182.3 \mu \mathrm{M}\left(\mathrm{NH}_{4}\right)_{2} \mathrm{SO}_{4}$, 91.6 $\mu \mathrm{M} \mathrm{KNO}, 273.9 \mu \mathrm{M} \mathrm{MgSO} \cdot 7 \mathrm{H}_{2} \mathrm{O}, 91.1 \mu \mathrm{M}$ $\mathrm{KH}_{2} \mathrm{PO}_{4}, 182.5 \mu \mathrm{M} \mathrm{Ca}\left(\mathrm{NO}_{3}\right)_{2}, 30.6 \mu \mathrm{M}$ Fe-citrate, $0.25 \mu \mathrm{M} \mathrm{H} \mathrm{H}_{3} \mathrm{BO}_{3}, 0.2 \mu \mathrm{M} \mathrm{MnSO}_{4} \cdot \mathrm{H}_{2} \mathrm{O}, 0.2 \mu \mathrm{M}$ $\mathrm{ZnSO}_{4} \cdot 7 \mathrm{H}_{2} \mathrm{O}, 0.05 \mu \mathrm{M} \mathrm{CuSO} \cdot 5 \mathrm{H}_{2} \mathrm{O}$, and $0.07 \mu \mathrm{M}$ $\mathrm{H}_{2} \mathrm{MoO}_{4}$. Kimura B solution contains the desired nutrient elements and has been widely used for growing rice plants. Since young rice seedlings were used for the present study, the nutrient solution contains no silicon, although silicon is essential for rice. The nutrient solutions $(\mathrm{pH} 4.7$ ) were replaced every 3 days. The hydroponically cultivated seedlings were grown in a Phytotron (Agricultural Experimental Station, National Taiwan University, Taipei, Taiwan) with natural sunlight at $30 / 25^{\circ} \mathrm{C}$ day/night and $90 \%$ relative humidity.

HS or $\mathrm{H}_{2} \mathrm{O}_{2}$ pretreatment and $\mathrm{Cd}$ treatment

Twelve-day-old seedlings with three leaves were exposed to $30^{\circ} \mathrm{C}$ (non-HS) and $45^{\circ} \mathrm{C}$ (HS) for $3 \mathrm{~h}$ in the dark. For $\mathrm{H}_{2} \mathrm{O}_{2}$ pretreatment, $0.5 \mathrm{mM} \mathrm{H}_{2} \mathrm{O}_{2}$ was added to nutrient solution for $3 \mathrm{~h}$ under non-HS conditions. Rice seedlings were then grown in basic nutrient solution with or without $5 \mu \mathrm{M} \mathrm{CdCl} 2$ under natural sunlight at $30 / 25^{\circ} \mathrm{C}$ day/night for 7 days. $\mathrm{Cd}$ toxicity was evaluated by the chlorosis and lipid peroxidation (increase in the content of malondialdehyde, MDA) of the second leaves.

\section{Determinations of MDA, GSH, and GSSG}

MDA was extracted with $5 \%(w / v)$ trichloroacetic acid and determined by the thiobabituric acid reaction as described by Heath and Packer (1968). GSH and GSSG in 3\% sulfosalicylic acid extract were analyzed according to Tsai et al. (2004). GSH and GSSG 
contents were expressed on the basis of initial fresh weight (FW).

Extraction and assays of ascorbate peroxidase (APX) and glutathione reductase GR) To measure APX and GR, leaf tissues were homogenized with $0.1 \mathrm{M}$ sodium phosphate buffer $(\mathrm{pH}$ 6.8) in a chilled pestle and mortar. For analysis of APX activity, $2 \mathrm{mM}$ ascorbate was added to the extraction buffer. The homogenate was centrifuged at $12,000 \mathrm{~g}$ for $20 \mathrm{~min}$ and the resulting supernatant was used for determination of enzyme activity and protein content. The whole extraction procedure was carried out at $4^{\circ} \mathrm{C}$. APX activity was determined according to Nakano and Asada (1981). One unit of activity for APX was defined as the amount of enzyme that degraded $1 \mu \mathrm{mol}$ of ASC per min. GR was determined by the method of Foster and Hess (1980). One unit of GR was defined as the amount of enzyme that decreased $1 A_{340}$ per min. The enzyme extracts were used for determination of protein by the method of Bradford (1976). Statistical analysis Statistical differences between measurements $(n=4)$ on different treatments or on different times were analyzed following LSD test.

\section{Results}

HS- and $\mathrm{H}_{2} \mathrm{O}_{2}$-induced Cd tolerance

To test if pretreatment of rice seedlings with HS would affect subsequent $\mathrm{Cd}$-induced toxicity of the second leaves, rice seedlings were pretreated with HS for $3 \mathrm{~h}$ under dark conditions and then treated with $5 \mu \mathrm{M} \mathrm{CdCl}_{2}$ for 7 days. It was observed that a 3-h HS pretreatment exhibited a complete reduction of $\mathrm{Cd}$ induced leaf chlorosis (Fig. 1a) and lipid peroxidation in the second leaves (Fig. 2a).

To examine the possible involvement of $\mathrm{H}_{2} \mathrm{O}_{2}$ in the protection of rice seedlings against $\mathrm{Cd}$ toxicity, rice seedlings were first pretreated with $0.5 \mathrm{mM} \mathrm{H}_{2} \mathrm{O}_{2}$ for $3 \mathrm{~h}$ and then transferred rice seedlings to nutrient solution with or without $5 \mu \mathrm{M} \mathrm{CdCl}$ for 7 days. Results demonstrated that the chlorosis and the increase in the content of MDA caused by $\mathrm{CdCl}_{2}$ were reduced by $\mathrm{H}_{2} \mathrm{O}_{2}$ pretreatment (Fig. $1 \mathrm{~b}$ and Fig. 2a). We also observed that $\mathrm{HS}$ or $\mathrm{H}_{2} \mathrm{O}_{2}$ pretreatment exhibited a reduction of Cd-decreased GSH content (Fig. 2b) and Cd-increased APX and GR activities (Fig. 2c,d) in rice leaves.

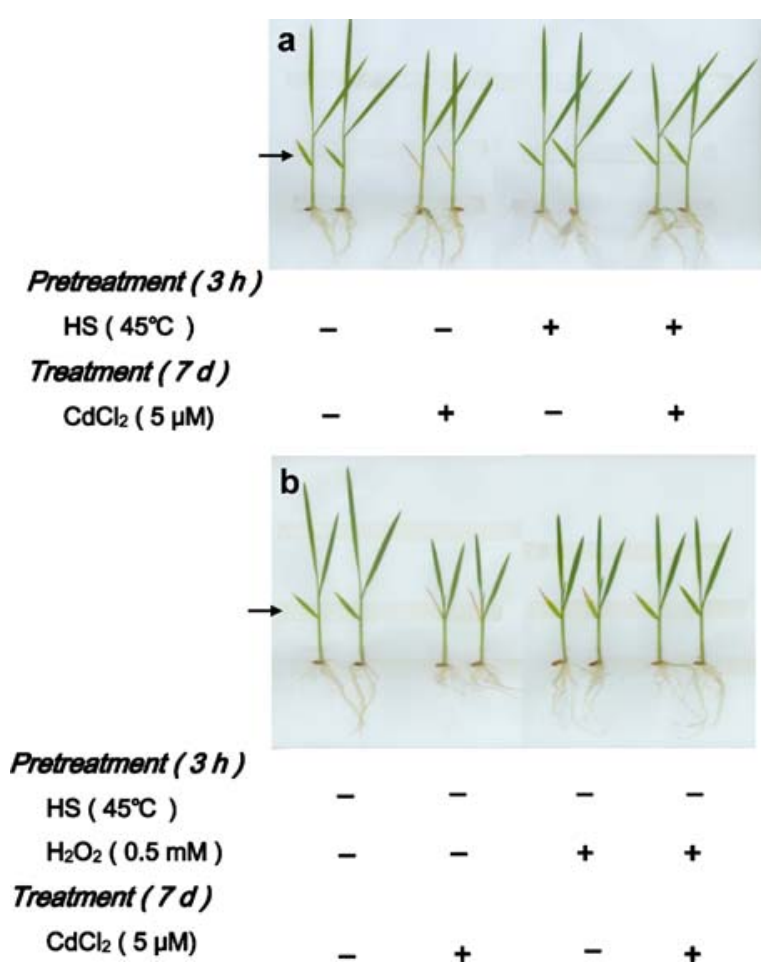

Fig. 1 Effect of $\mathrm{CdCl}_{2}$ on chlorosis in the second leaves of rice seedlings pretreated with $\mathrm{HS}$ a and $\mathrm{H}_{2} \mathrm{O}_{2}$ b. Rice seedlings were pretreated with $\mathrm{HS}\left(45^{\circ} \mathrm{C}\right)$ or $0.5 \mathrm{mM} \mathrm{H}_{2} \mathrm{O}_{2}$ under non-HS $\left(30^{\circ} \mathrm{C}\right)$ conditions for $3 \mathrm{~h}$ and then treated with or without $5 \mu \mathrm{M}$ $\mathrm{CdCl}_{2}$ for 7 days. Arrow indicates the second leaves

GSH content and the GSH/GSSG ratio in HSand $\mathrm{H}_{2} \mathrm{O}_{2}$-treated leaves

Not only GSH content but also the GSH/GSSG ratio was increased in leaves of rice seedlings pretreated with $\mathrm{HS}$ or $\mathrm{H}_{2} \mathrm{O}_{2}$ (Fig. 3). These results suggest that GSH may play an important role in HSand $\mathrm{H}_{2} \mathrm{O}_{2}$-induced tolerance of rice to subsequent Cd stress.

\section{Pretreatment with GSH under non-HS conditions}

GSH content was increased in leaves of rice seedlings pretreated with $1 \mathrm{mM} \mathrm{GSH}$ under non-HS conditions (Fig. 4a). It is also shown that APX and GR activities were increased in leaves of rice seedlings pretreated with GSH under non-HS conditions (Fig. 4b,c). When rice seedlings pretreated with GSH under non-HS conditions were transferred to nutrient solution with or without $5 \mu \mathrm{M} \mathrm{CdCl}_{2}$ for 7 days, Cd tolerance was greatly improved (Fig. 5a,b). 
Fig. 2 Effect of $\mathrm{CdCl}_{2}$ on the contents of MDA a and GSH $\mathbf{b}$ and the activities of APX $\mathbf{c}$ and GR $\mathbf{d}$ in the second leaves of rice seedlings pretreated with HS and $\mathrm{H}_{2} \mathrm{O}_{2}$. Rice seedlings were pretreated with $\mathrm{HS}\left(45^{\circ} \mathrm{C}\right)$ or $0.5 \mathrm{mM} \mathrm{H}_{2} \mathrm{O}_{2}$ under nonHS conditions for $3 \mathrm{~h}$ and then treated with or without $5 \mu \mathrm{M} \mathrm{CdCl}_{2}$ for 7 days. Bars indicate standard error $(n=4)$. Values with the same letter are not significantly different at $P<0.05$
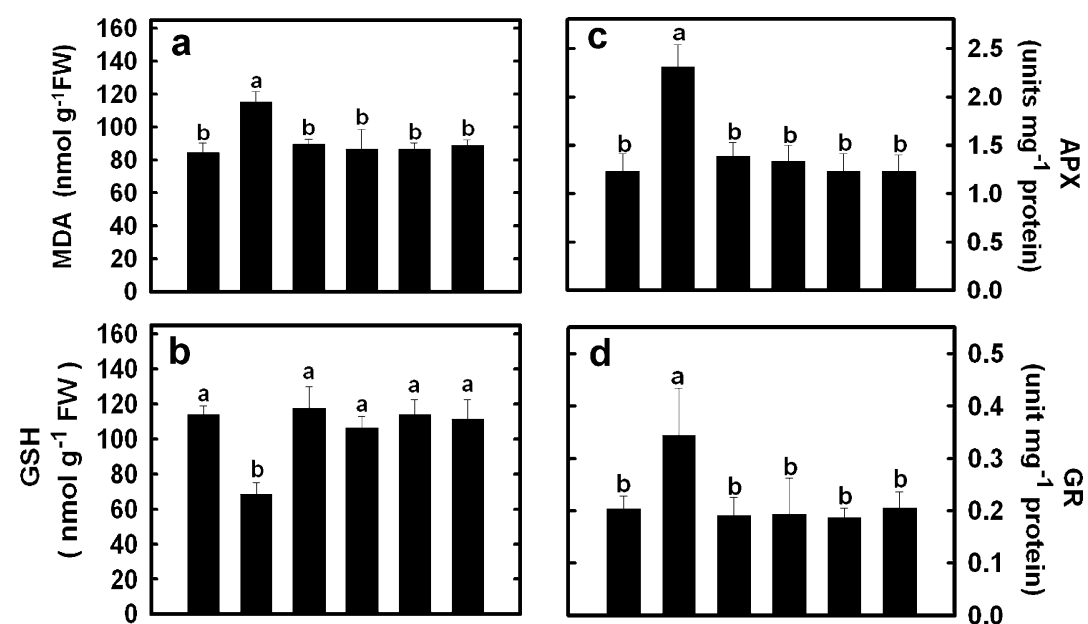

Pretreatment (3h)

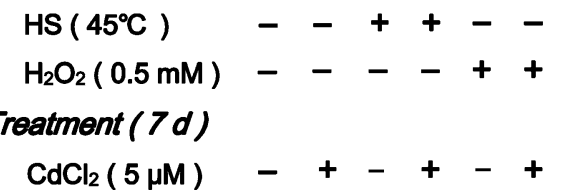

\section{Pretreatment with BSO}

BSO is a specific and potent inhibitor of $\gamma$-ECS (Griffith and Meister 1979). When rice seedlings were pretreated
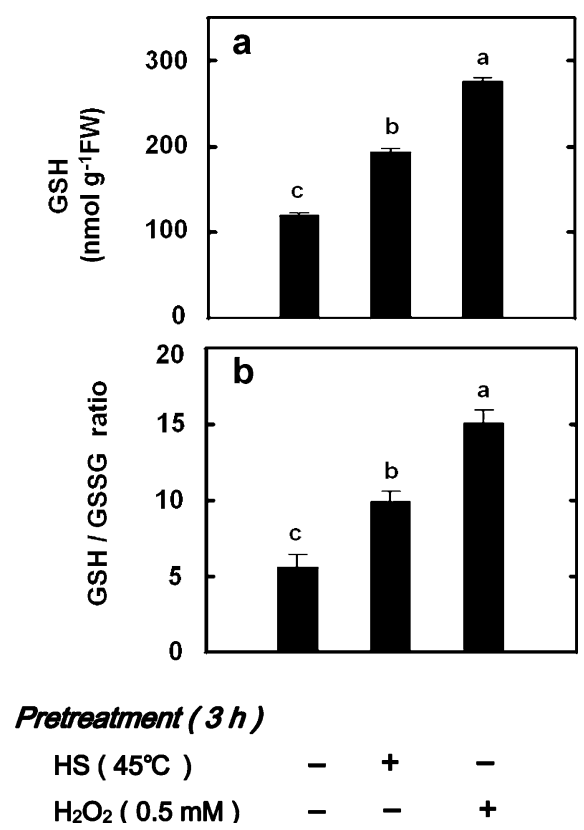

Fig. 3 Effect of $\mathrm{HS}$ and $\mathrm{H}_{2} \mathrm{O}_{2}$ on GSH content a and the GSH/ GSSG ratio $\mathbf{b}$ in the second leaves of rice seedlings. Rice seedlings were treated with $\mathrm{HS}\left(45^{\circ} \mathrm{C}\right)$ or $0.5 \mathrm{mM} \mathrm{H} \mathrm{H}_{2} \mathrm{O}_{2}$ under non-HS conditions for 3 h. Bars indicate standard error $(n=4)$. Values with the same letter are not significantly different at $P<0.05$ with $0.5 \mathrm{mM}$ BSO for $3 \mathrm{~h}$ under HS conditions, the second leaves had lower GSH content than those pretreated without BSO under HS conditions (Fig. 6a). Results also show that that activities of APX and GR were decreased in leaves of rice seedlings pretreated with BSO under HS conditions (Fig. 6b,c). To confirm the involvement of GSH in HS-induced Cd tolerance, BSO-pretreated rice seedlings under HS conditions were transferred to nutrient solution with $5 \mu \mathrm{M} \mathrm{CdCl}_{2}$ for 7 days. It was observed that pretreatment of rice seedlings with BSO under HS condition enhanced $\mathrm{Cd}$ toxicity (Fig. 7a,b). The effects of BSO under HS conditions on the content of $\mathrm{GSH}$, the activities of APX and GR, and the toxicity of Cd were reversed by the application of GSH (Fig. 6 and Fig. 7).

The increase in the content of GSH and the activities of APX and GR in leaves caused by $\mathrm{H}_{2} \mathrm{O}_{2}$ was reduced by the addition of BSO (Fig. 8a,b,c). Interestingly, rice seedlings pretreated with $\mathrm{H}_{2} \mathrm{O}_{2}+$ $\mathrm{BSO}$ were less tolerant to subsequent $\mathrm{Cd}$ stress than those pretreated with $\mathrm{H}_{2} \mathrm{O}_{2}$ only (Fig. 9a,b). The effects of $\mathrm{BSO}$ on $\mathrm{H}_{2} \mathrm{O}_{2}$-increased $\mathrm{GSH}$ content, APX and GR activities, and $\mathrm{Cd}$ toxicity can be restored by the addition of GSH (Fig. 8 and Fig. 9).

Change in $\mathrm{H}_{2} \mathrm{O}_{2}$ and $\mathrm{GSH}$ contents during $\mathrm{HS}$

Changes in $\mathrm{H}_{2} \mathrm{O}_{2}$ and $\mathrm{GSH}$ contents after exposure rice seedlings to HS were evaluated. As shown in 

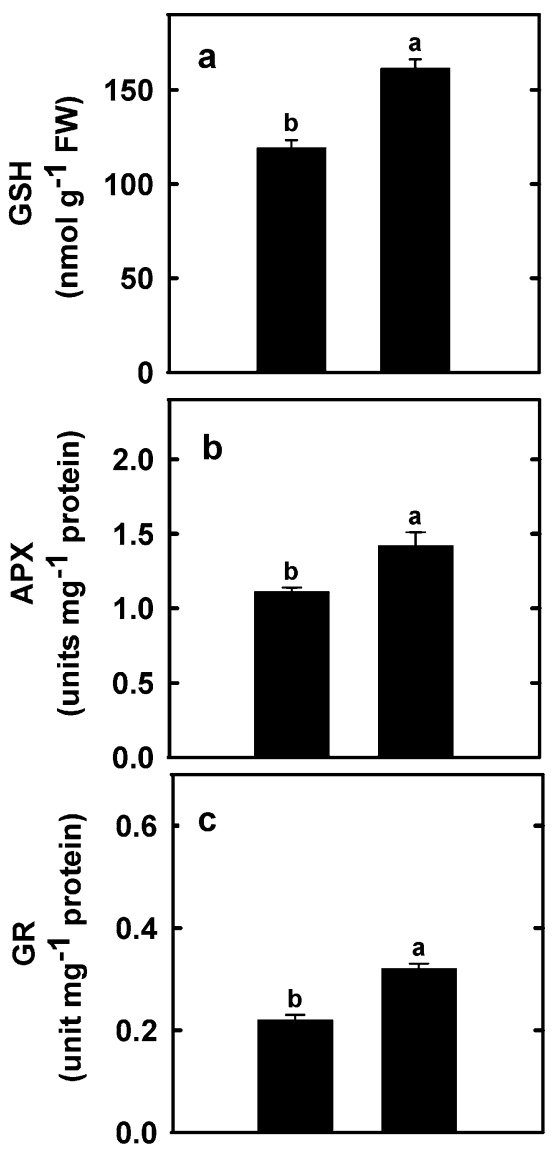

\section{Pretreatment $(3 \mathrm{~h})$}

\section{$\mathrm{HS}\left(45^{\circ} \mathrm{C}\right)$ GSH ( $1 \mathrm{mM}$ )}

Fig. 4 Effect of GSH pretreatment on the content of GSH a and the activities of APX $\mathbf{b}$ and GR $\mathbf{c}$ in the second leaves of rice seedlings. Rice seedlings were pretreated with $1 \mathrm{mM} \mathrm{GSH}$ for $3 \mathrm{~h}$ under non-HS conditions. Bars indicate standard error $(n=4)$. Values with the same letter are not significantly different at $P<0.05$

(Fig. 10a), $\mathrm{H}_{2} \mathrm{O}_{2}$ content increased in leaves $1 \mathrm{~h}$ after HS exposure and subsequently decreased slightly. GSH content in leaves of HS seedlings was higher than their respective non-HS, but it occurred $3 \mathrm{~h}$ after treatment (Fig. 10b).

\section{Discussion}

The most general symptom of Cd toxicity of plants is leaf chlorosis (Das et al. 1997). When rice seedlings were treated with $\mathrm{CdCl}_{2}$, chlorosis was first observed in the second leaves (Hsu and Kao 2003). The formation of MDA (thiobarbituric acid reactive substances) is an indicator of ROS generation in the tissues, and it may be used as a reliable index of lipid peroxidation in biological systems (Heath and Packer 1968). In our previous work, it has been shown that $\mathrm{Cd}$ can induce oxidative stress in rice leaves, characterized by an increase in the content of MDA (Hsu and Kao 2005; Kuo and Kao 2004). Thus, in the present study, Cd toxicity was assessed by the chlorosis and lipid peroxidation of the second leaves. On the basis of these criteria, we demonstrated that HS pretreatment protected rice seedlings from subsequent stress caused by $5 \mu \mathrm{M} \mathrm{CdCl}$ (Fig. 1a and Fig. 2a). It has previously been shown that $\mathrm{Cd}$ treatment causes a decrease in APX and GR activities in leaves of rice seedlings (Hsu and Kao 2005; Kuo and Kao 2004). Here we observed that these Cd-
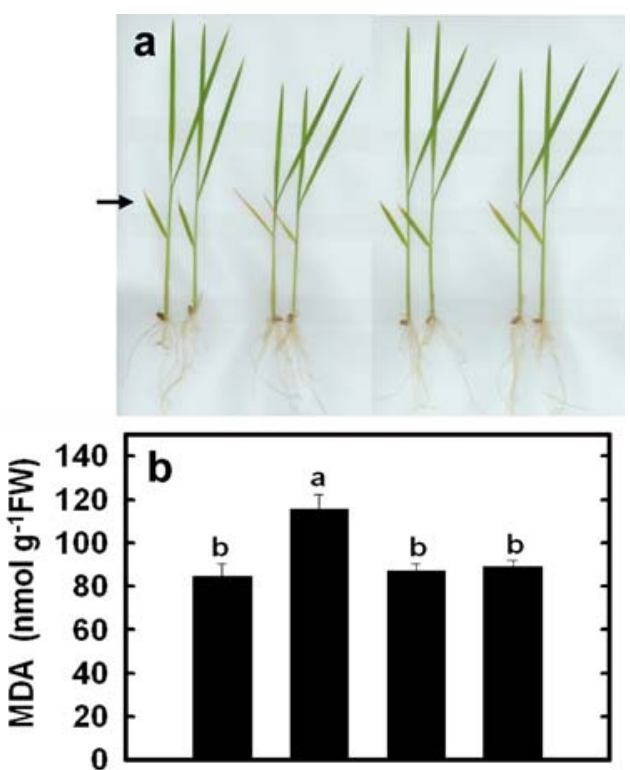

Pretreatment ( $3 h$ )

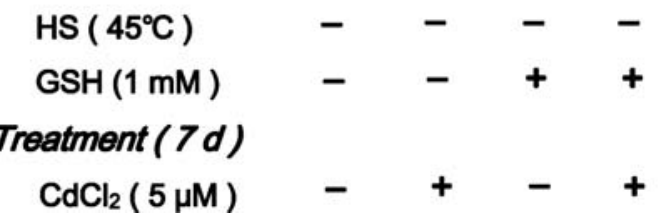

Fig. 5 Effect of $\mathrm{CdCl}_{2}$ on chlorosis and lipid peroxidation in the second leaves of rice seedlings pretreated with or without GSH. Rice seedlings were pretreated with $1 \mathrm{mM}$ GSH under non-HS $\left(30^{\circ} \mathrm{C}\right)$ conditions for $3 \mathrm{~h}$ and then treated with or without $5 \mu \mathrm{M} \mathrm{CdCl}_{2}$ for 7 days. Arrow indicates the second leaves 

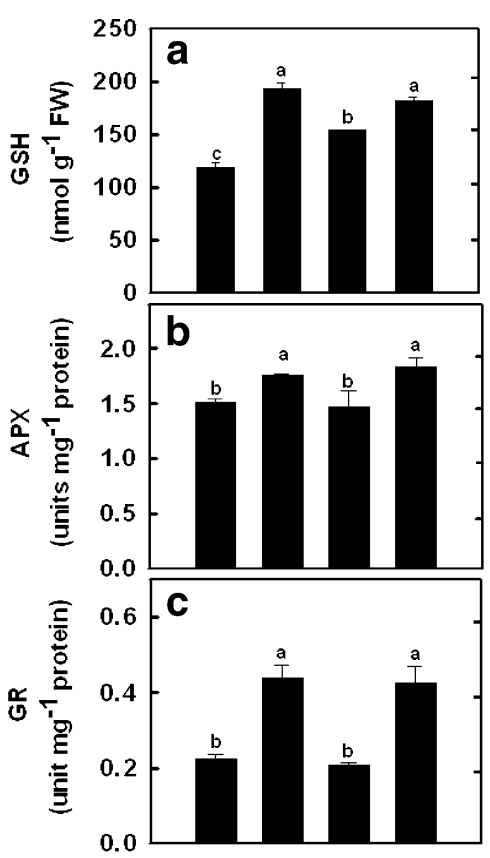

Pretreatment ( $3 h$ )

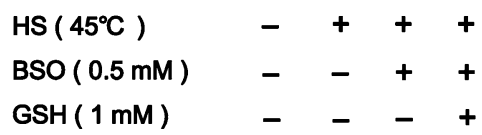

Fig. 6 Effect of BSO and GSH pretreatments on the content of GSH $\mathbf{a}$ and the activities of APX $\mathbf{b}$ and GR (c) in the second leaves of rice seedlings under $\mathrm{HS}\left(45^{\circ} \mathrm{C}\right)$ conditions. All measurements were made $3 \mathrm{~h}$ after pretreatment. The concentrations of GSH and BSO are $1 \mathrm{mM}$ and $0.5 \mathrm{mM}$, respectively. Bars indicate standard error $(n=4)$. Values with the same letter are not significantly different at $P<0.05$

induced changes can be reduced by a HS pretreatment (Fig. 2b,c,d). We have recently reported that a 3-h HS exposure prevents the toxicity of high $\mathrm{CdCl}_{2}$ concentrations $(50 \mu \mathrm{M}$ and $500 \mu \mathrm{M})$ (Hsu and Kao 2007b). Basically, our results are in agreement with the idea that HS protects against Cd-dependent oxidative stress (Gong et al. 2001; Orzech and Burke 1988).

GSH plays an important role in physiological functions such as redox regulation, conjugation of metabolites, detoxification of xenobiotics and homeostasis and cellular signaling that trigger adaptive responses (Foyer and Noctor 2005; Noctor et al. 2002; Rouhier et al. 2008). Years ago it has been shown that GSH in mammalian cells increases during HS (Mitchel et al. 1983). Nieto-Sotelo and Ho (1986) were the first to show that elevated synthesis of GSH occurs during HS in plant cells. In the present study, we demonstrated that GSH content and the GSH/GSSG ratio increased in leaves of rice seedlings pretreated with HS (Fig. 3). We also observed that BSO reduced HSinduced GSH accumulation (Fig. 6a), suggesting that HS-increased GSH content may be due to the increase in GSH synthesis. Yu et al. (2002, 2003) demonstrated that $\mathrm{H}_{2} \mathrm{O}_{2}$ treatment induced GSH accumulation in mung bean and Phalaenopsis. Our results also show that $\mathrm{H}_{2} \mathrm{O}_{2}$ treatment was able to increase the synthesis of GSH under non-HS conditions (Fig. 3, Fig. 8a).

Several authors have shown that an elevated GSH content is correlated with the ability of plants to withstand Cd-induced oxidative stress (Chen and Goldsbrough 1994; Chen and Kao 1995b; Howden et al. 1995; Pilon-Smits et al. 2000; Rüegsegger et al.1990; Xiang et al. 2001; Zhu et al. 1999). The present study indicates that $\mathrm{HS}$-and $\mathrm{H}_{2} \mathrm{O}_{2}$-induced protection against subsequent $\mathrm{Cd}$ stress of rice seedlings are mediated through GSH. This conclusion was based on the observations that (i) $\mathrm{HS}-$ and $\mathrm{H}_{2} \mathrm{O}_{2}-$ pretreatment resulted in an increase in GSH content in leaves of rice seedlings (Fig. 3) and enhancement of subsequent $\mathrm{Cd}$ tolerance (Fig. 1 and Fig. 2), (ii) exogenous application of GSH under non-HS conditions, which resulted in an increase in GSH in leaves (Fig. 4 a), enhanced subsequent $\mathrm{Cd}$ tolerance

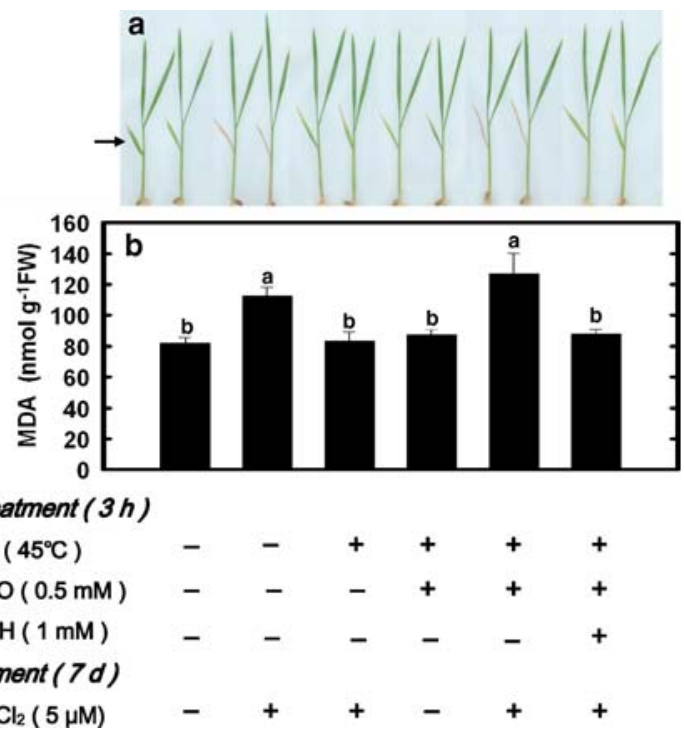

Fig. 7 Effect of $\mathrm{CdCl}_{2}$ on chlorosis a and lipid peroxidation b in the second leaves of rice seedlings pretreated with $\mathrm{BSO}$ and $\mathrm{BSO}+\mathrm{GSH}$ under $\mathrm{HS}\left(45^{\circ} \mathrm{C}\right)$ conditions. Rice seedlings were pretreated with $\mathrm{BSO}$ and $\mathrm{BSO}+\mathrm{GSH}$ for $3 \mathrm{~h}$ and then treated with $\mathrm{CdCl}_{2}$ for 7 days. The concentrations of GSH, BSO, and $\mathrm{CdCl}_{2}$ are $1 \mathrm{mM}, 0.5 \mathrm{mM}$, and $5 \mu \mathrm{M}$, respectively. Arrow indicates the second leaves 

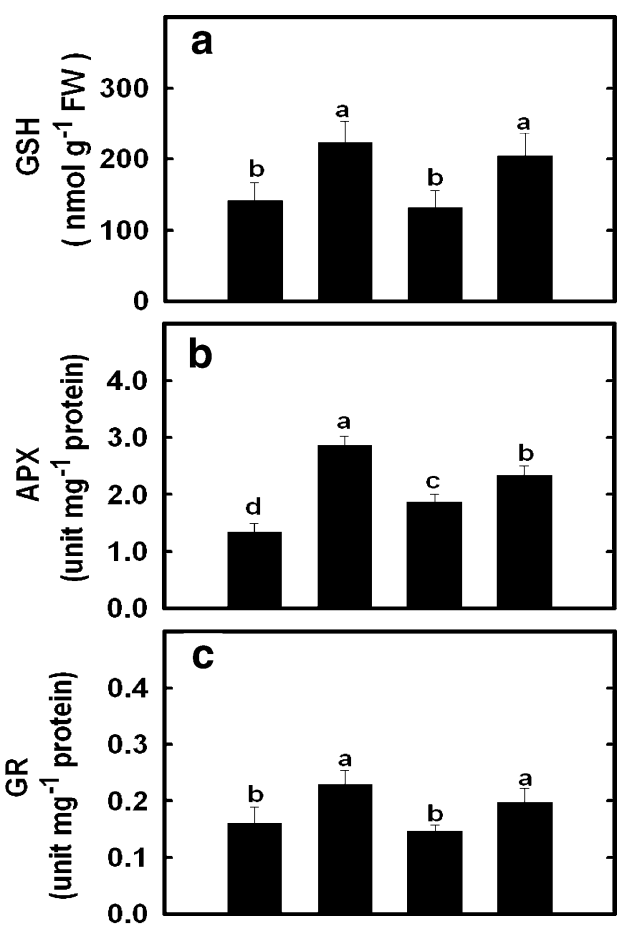

Pretreatment ( $3 h$ )

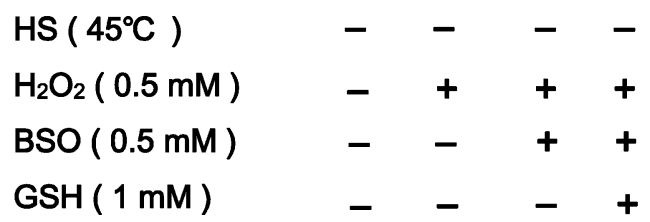

Fig. 8 Effect of $\mathrm{H}_{2} \mathrm{O}_{2}$, BSO, and $\mathrm{BSO}+\mathrm{GSH}$ pretreatments on the content of GSH $\mathbf{a}$ and the activities of APX $\mathbf{b}$ and GR $\mathbf{c}$ in the second leaves of rice seedlings under non-HS $\left(30^{\circ} \mathrm{C}\right)$ conditions. All measurements were made $3 \mathrm{~h}$ after pretreatment. The concentrations of $\mathrm{H}_{2} \mathrm{O}_{2}, \mathrm{GSH}$ and $\mathrm{BSO}$ are $0.5 \mathrm{mM}$, $1 \mathrm{mM}$, and $0.5 \mathrm{mM}$, respectively. Bars indicate standard error $(n=4)$. Values with the same letter are not significantly different at $P<0.05$

of rice seedlings (Fig. 5), (iii) BSO, a specific inhibitor of GSH synthesis (Griffith and Meister 1979), pretreatment, which effectively inhibited the increase GSH content caused by HS (Fig. 6a) and $\mathrm{H}_{2} \mathrm{O}_{2}$ (Fig. 8a), reduced subsequent $\mathrm{Cd}$ tolerance (Fig. 7 and Fig. 9), and (iv) the effect of BSO on HSand $\mathrm{H}_{2} \mathrm{O}_{2}$-induced GSH accumulation and toxicity to subsequent $\mathrm{Cd}$ stress can be reversed by the addition of GSH (Fig 6a, Fig. 7, Fig. 8, and Fig. 9).

The involvement of GSH as an inducer of the stress response has been described before (Hérouart et al. 1993; Noctor et al. 2002; Wingsle and Karpinski 1996). In their work with maize seedlings, Kocsy et al.
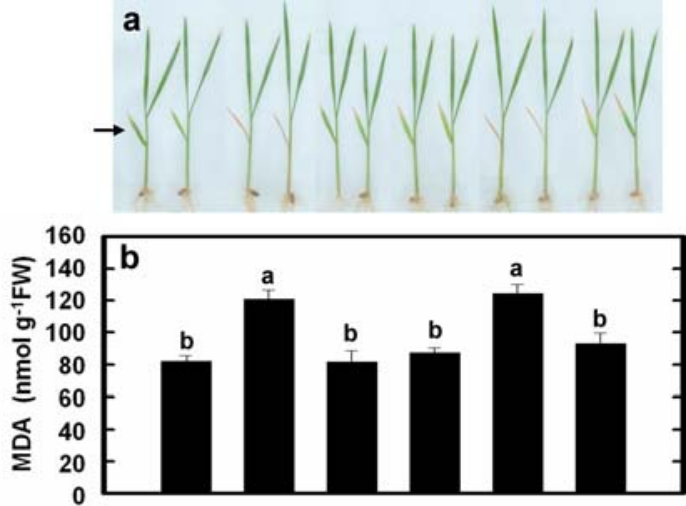

Pretreatment $(3 \mathrm{~h})$

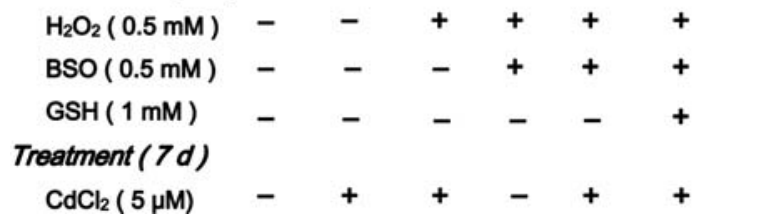

Fig. 9 Effect of $\mathrm{CdCl}_{2}$ on chlorosis a and lipid peroxidation $\mathbf{b}$ in the second leaves of rice seedlings pretreated with $\mathrm{H}_{2} \mathrm{O}_{2}$, $\mathrm{BSO}$ or $\mathrm{BSO}+\mathrm{GSH}$ under non-HS $\left(30^{\circ} \mathrm{C}\right)$ conditions. Rice seedlings were pretreated with $\mathrm{BSO}$ and $\mathrm{BSO}+\mathrm{GSH}$ for $3 \mathrm{~h}$ and then treated with $\mathrm{CdCl}_{2}$ for 7 days. The concentrations of $\mathrm{GSH}, \mathrm{BSO}$, and $\mathrm{CdCl}_{2}$ are $1 \mathrm{mM}, 0.5 \mathrm{mM}$, and $5 \mu \mathrm{M}$, respectively. Arrow indicates the second leaves
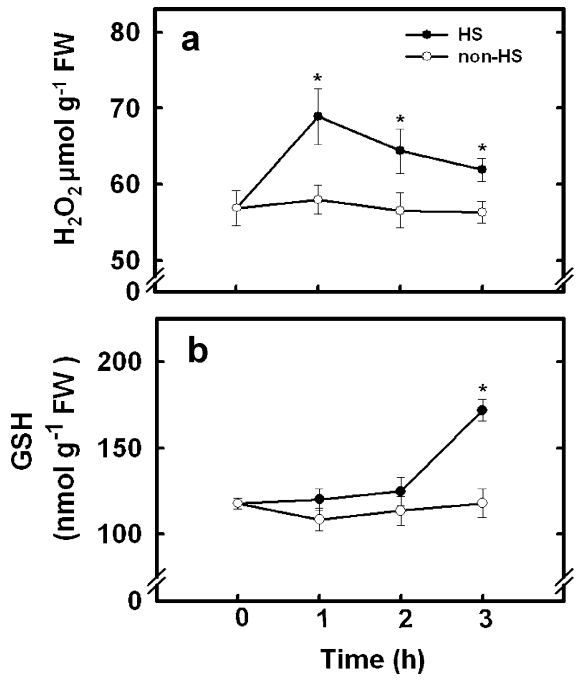

Fig. 10 Changes in the contents of $\mathrm{H}_{2} \mathrm{O}_{2}$ a and GSH $\mathbf{b}$ in the second leaves of rice seedlings treated with or without $\mathrm{HS}\left(45^{\circ} \mathrm{C}\right)$ under dark conditions. Seedlings were exposed to HS for 1, 2, and $3 \mathrm{~h}$ and the second leaves were taken for determination of $\mathrm{H}_{2} \mathrm{O}_{2}$ and $\mathrm{GSH}$ contents. Bars indicate standard error $(n=4)$. Values with the same letter are not significantly different at $P<$ 0.05 
(2000, 2001) established a linear relationship between GSH content and GR activity. Here, we observed that treatment with GSH under non-HS conditions resulted in an increase in the content of GSH and the activities of APX and GR in leaves of rice seedlings (Fig. 4). BSO treatment, which reduced the content of GSH in leaves of rice seedlings increased by $\mathrm{HS}$ and $\mathrm{H}_{2} \mathrm{O}_{2}$ treatments (Fig. 6a and Fig. 8a), caused the decrease in the activities of APX and GR (Fig. 6b,c and Fig. 8b,c). The effect of BSO on the content of GSH and the activities of APX and GR was reversed by the application of exogenous GSH (Fig. 6 and 8). It appears that GSH is involved in regulating the activities of APX and GR in rice leaves.

The time courses of responses after HS (Fig. 10) suggest that the following sequence of events may take place: $\mathrm{HS} \rightarrow \mathrm{H}_{2} \mathrm{O}_{2} \rightarrow$ GSH. Exogenously supplied $\mathrm{H}_{2} \mathrm{O}_{2}$ to rice seedlings under non-HS conditions also increased GSH content (Fig. 3) and protected against subsequent $\mathrm{Cd}$ stress (Fig. 1b and Fig. 2). All these results have led us to conclude that early accumulation of $\mathrm{H}_{2} \mathrm{O}_{2}$ during $\mathrm{HS}$ signals the increase in GSH content, which in turn prevents rice seedlings from oxidative damage by $\mathrm{Cd}$.

Acknowledgements This work was supported by a research grant of the National Science Council of the Republic of China (NSC 96-2628- B-002-001)

\section{References}

Azevedo Neto AD, Prisco JT, Enéas-Filho J, Medeiros J-VR, Gomes-Filho E (2005) Hydrogen peroxide pre-treatment induces salt-stress acclimation in maize plants. J Plant Physiol 162:1114-1122 doi:10.1016/j.jplph.2005.01.007

Bradford MM (1976) A rapid and sensitive method for the quantitation of microgram quantities of protein utilizing the principle of protein-dye binding. Anal Biochem 72:248-254 doi:10.1016/0003-2697(76)90527-3

Chen J, Goldsbrough PB (1994) Increased activity of $\gamma$ glutamylcysteine synthetase in tomato cells selected for cadmium tolerance. Plant Physiol 106:233-239

Chen SL, Kao CH (1995a) Prior temperature exposure affects subsequent $\mathrm{Cd}$-induced ethylene production in rice leaves. Plant Sci 104:135-138 doi:10.1016/0168-9452(94)04027-E

Chen SL, Kao CH (1995b) Glutathione reduces the inhibition of rice seedling root growth caused by cadmium. Plant Growth Regul 16:249-252 doi:10.1007/BF00024781

Chen Z, Silva H, Klessig RF (1993) Active oxygen species in the induction of plant systemic acquired resistance by salicylic acid. Science 262:1883-1886 doi:10.1126/ science. 8266079
Cho U-H, Seo N-H (2005) Oxidative stress in Arabidopsis thaliana exposed cadmium is due to hydrogen peroxide accumulation. Plant Sci 168:113-120 doi:10.1016/j. plantsci.2004.07.021

Das P, Samantaray S, Rout GR (1997) Studies on cadmium toxicity in plants. Environ Pollut 98:29-36 reviewdoi:10.1016/S0269-7491(97)00110-3

Dat JF, Foyer CH, Scott IM (1998) Changes in salicylic acid and antioxidants during induced thermotolerance in mustard seedlings. Plant Physiol 118:1455-1461 doi:10.1104/ pp.118.4.1455

Foster JG, Hess JL (1980) Response of superoxide dismutase and glutathione reductase activities in cotton leaf tissue exposed to an atmosphere enriched in oxygen. Plant Physiol 66:482-487

Foyer CH, Noctor G (2005) Oxidant and antioxidant signaling in plants: a re-evaluation of the concept of oxidative stress in a physiological context. Plant Cell Environ 28:10561071 doi:10.1111/j.1365-3040.2005.01327.x

Garnier L, Simon-Plas F, Thuleau P, Agnel J-P, Blein J-P, Ranjeva R, Montillet J-L (2006) Cadmium affects tobacco cells by a series of three waves of reactive oxygen species that contribute to cytotoxicity. Plant Cell Environ 29:1956-1969 doi:10.1111/j.1365-3040.2006. 01571.x

Gechev T, Gadjev I, Van Breusegem F, Inzé D, Dukiandjiev S, Toneva V, Minkov I (2002) Hydrogen peroxide protects tobacco from oxidative stress by inducing a set of antioxidant enzymes. Cell Mol Life Sci 59:708-714 doi:10.1007/s00018-002-8459-x

Gong M, Chen B, Li X-G, Guo L-H (2001) Heat-shockinduced cross adaptation to heat, chilling, drought and salt stress in maize seedlings and involvement of $\mathrm{H}_{2} \mathrm{O}_{2}$. J Plant Physiol 158:1125-1130 doi:10.1078/0176-1617-00327

Greger M, Landberg T (2008) Role of rhizosphere mechanisms in Cd uptake by various wheat cultivars. Plant Soil doi10.1007/s11104-008-9725-y

Griffith OW, Meister A (1979) Potent and specific inhibition of glutathione synthesis by buthionine sulfoximine (S- $n$-butyl homocysteine sulfoximine). J Biol Chem 254:7558-7560

Heath RL, Packer L (1968) Photoperoxidation in isolated chlorplasts I. Kinetics and stoichiometry of fatty acid peroxidation. Arch Biochem Biophys 125:189-198 doi:10.1016/0003-9861 (68)90654-1

Hérouart D, Van Montagu M, Inzé D (1993) Redox-activated expression of the cytosolic copper/zinc superoxide dismutase gene in Nicotiana. Proc Natl Acad Sci USA 90:3108-3112 doi:10.1073/pnas.90.7.3108

Howden R, Andersen CR, Goldsbrough PB, Cobbett CS (1995) A cadmium-sensitive, glutathione-deficient of Arabidopsis thaliana. Plant Physiol 107:1067-1073 doi:10.1104/ pp.107.4.1067

Hsu YT, Kao CH (2003) Role of abscisic acid in cadmium tolerance of rice (Oryza sativa L.) seedlings. Plant Cell Environ 26:867-874 doi:10.1046/j.1365-3040.2003.01018.x

Hsu YT, Kao CH (2005) Abscisic acid accumulation and cadmium tolerance in rice seedlings. Physiol Plant 124:71-80 doi:10.1111/j.1399-3054.2005.00490.x

Hsu YT, Kao CH (2007a) Toxicity in leaves of rice exposed to cadmium is due to hydrogen peroxide accumulation. Plant Soil 298:231-241 doi:10.1007/s11104-007-9357-7 
Hsu YT, Kao CH (2007b) Heat shock-mediated $\mathrm{H}_{2} \mathrm{O}_{2}$ accumulation and protection against $\mathrm{Cd}$ toxicity in rice seedlings. Plant Soil 300:137-147 doi:10.1007/s11104-007-9396-0

Jarvis SC, Jones LHP, Hopper MJ (1976) Cadmium uptake from solution by plants and its transport from roots to shoots. Plant Soil 44:179-191 doi:10.1007/BF00016965

Kocsy G, von Ballmoos P, Suter M, Rüegsegger A, Galli U, Szalai G, Galiba G, Brunold C (2000) Inhibition of glutathione synthesis reduces chilling tolerance in maize. Planta 211:528-536 doi:10.1007/s004250000308

Kocsy G, von Ballmoos P, Rüegsegger A, Szalai G, Galiba G, Brunold C (2001) Increasing the glutathione content in a chilling-sensitive maize genotype using safeners increased protection against chilling-induced injury. Plant Physiol 127:1147-1156 doi:10.1104/pp.127.3.1147

Kuo MC, Kao CH (2004) Antioxidant enzyme activities are upregulated in response to cadmium in sensitive, but not in tolerant rice (Oryza sativa L.) seedlings. Bot Bull Acad Sin 45:291-299

Lopez-Delgado H, Dat JF, Foyer C, Scott IM (1998) Induction of thermotolerance in potato microplants by acetylsalicylic acid and $\mathrm{H}_{2} \mathrm{O}_{2}$. J Exp Bot 49:713-720 doi:10.1093/jexbot/ 49.321 .713

Mendoza-Cózatl D, Loza-tavera H, Hernández-Navarro A, Moreno-Sánchez R (2005) Sulfur metabolism and glutathione metabolism under cadmium stress in yeast, protists and plants. FEMS Microbiol Rev 29:653-671 doi:10.1016/j. femsre.2004.09.004

Mitchell JB, Russo A, Kinsella TJ, Glatstein E (1983) Glutathione elevation during thermotolerance induction and thermosensitization by glutathione depletion. Cancer Res 43:987-991

Nakano Y, Asada K (1981) Hydrogen peroxide is scavenged by ascorbate-specific peroxidase in spinach chloroplasts. Plant Cell Physiol 22:867-880

Neumann D, Lichtenberger O, Günther D, Tschiersch K, Nover L (1994) Heat-shock proteins induce heavy-metal tolerance in higher plants. Planta 194:360-367 doi:10.1007/ BF00197536

Nieto-Sotelo J, Ho T-HD (1986) Effect of heat shock on the metabolism of glutathione in maize roots. Plant Physiol 82:1031-1035

Noctor G, Foyer CH (1998) Ascorbate and glutathione: keeping active oxygen under control. Annu Rev Plant Physiol Plant Mol Biol 49:249-279 doi:10.1146/annurev. arplant.49.1.249

Noctor G, Gomez L, Vanacker H, Foyer CH (2002) Interaction between biosynthesis, compartmentation and transport in the control glutathione homeostasis and signalling. J Exp Bot 53:1283-1304 doi:10.1093/jexbot/53.372.1283

Orzech KA, Burke JJ (1988) Heat shock and the protection against metal toxicity in wheat leaves. Plant Cell Environ 11:711-714 doi:10.1111/j.1365-3040.1988.tb01154.x

Pilon-Smits EAH, Zhy YL, Sears T, Terry N (2000) Overexpression of glutathione reductase in Brassica juncea: effects of cadmium accumulation and tolerance. Physiol Plant 110:455-460 doi:10.1111/j.1399-3054.2000.1100405.x

Prasad TK, Anderson MD, Martin BA, Stewart CR (1994a) Evidence for chilling-induced oxidative stress in maize seedlings and a regulatory role for hydrogen peroxide. Plant Cell 6:65-74

Prasad TK, Anderson MD, Stewart CR (1994b) Acclimation, hydrogen peroxide, and abscisic acid protect mitochondria against irreversible chilling injury in maize seedlings. Plant Physiol 105:619-627

Rouhier N, Lemoire SD, Jacquot JP (2008) The role of glutathione in photoxynthetic organisms: emerging functions for glutaredoxins and glutathionylation. Annu Rev Plant Biol 59:143-166 doi:10.1146/annurev.arplant.59. 032607.092811

Rüegsegger A, Schmutrz E, Brunold C (1990) Regulation of glutathione synthesis by cadmium in Pisum sativum L. Plant Physiol 93:1579-1584

Schützendübel A, Polle A (2002) Plant responses to abiotic stresses: heavy metal-induced oxidative stress and protection by mycorrhization. J Exp Bot 53:1351-1355 doi:10.1093/ jexbot/53.372.1351

Tsai Y-C, Hong C-Y, Liu L-F, Kao CH (2004) Relative importance of $\mathrm{Na}^{+}$and $\mathrm{Cl}^{-}$in $\mathrm{NaCl}$-induced antioxidant systems in roots of rice seedlings. Physiol Plant 122:86-94 doi:10.1111/j.1399-3054.2004.00387.x

Uchida A, Jagendorf AT, Hibino T, Takabe T, Takabe T (2002) Effects of hydrogen peroxide and nitric oxide on both salt and heat stress tolerance in rice. Plant Sci 163:515-523 doi:10.1016/S0168-9452(02)00159-0

Wahid A, Perveen M, Gelani S, Basra SMA (2007) Pretreatment of seed with $\mathrm{H}_{2} \mathrm{O}_{2}$ improves salt tolerance of wheat seedlings by alleviation of oxidative damage and expression of stress proteins. J Plant Physiol 164:83-294 doi:10.1016/j.jplph.2006.01.005

Wingsle G, Karpinski S (1996) Differeential redox regulation by glutathione of glutathione redutase and $\mathrm{CuZn}$-superoxide dismutase gene expression in Pinus sylvestris L. needles. Planta 198:151-157 doi:10.1007/BF00197598

Xiang C, Werner BL, Christensen EM, Oliver DJ (2001) The biological functions of glutathione revisited in Arabidopsis transgenic plants with altered glutathione levels. Plant Physiol 126:564-574 doi:10.1104/pp.126.2.564

Yu C-W, Murphy TM, Sung W-W, Lin C-H (2002) $\mathrm{H}_{2} \mathrm{O}_{2}$ treatment induced glutathione accumulation and chilling tolerance in mung bean. Funct Plant Biol 29:1081-108 doi:10.1071/PP01264

Yu C-W, Murphy TM, Lin C-H (2003) Hydrogen peroxideinduced chilling tolerance in mung beans mediated through ABA-independent glutathione accumulation. Funct Plant Biol 30:955-963 doi:10.1071/FP03091

Zhu YL, Pilon-Smits EAH, Jouanin L, Terry N (1999) Overexpression of glutathione synthetase in Indian mustard enhances cadmium accumulation and tolerance. Plant Physiol 119:73-79 